\title{
Oocyte quality and ABO blood group system: are they connected?
}

\section{Sasikala Thanga Natarajamani ${ }^{1 *}$, Deepa Thiagarajamurthy ${ }^{2}$, Mahalakshmi Subramanian ${ }^{1}$, Janani Dakshina Moorthy ${ }^{1}$, Archana Bhargav ${ }^{1}$, P. J. Parameaswari ${ }^{1}$}

${ }^{1}$ Department of Assisted Reproduction, Crea Conceptions (P) Ltd., T Nagar, Chennai-17, Tamil Nadu, India

${ }^{2}$ Sai Womens Clinic, Adyar, Chennai-600020, Tamil Nadu, India

Received: 01 April 2015

Accepted: 09 May 2015

\section{*Correspondence:}

Dr. Sasikala Thanga Natarajamani,

E-mail: sasikala@creaconceptions.com

Copyright: (C) the author(s), publisher and licensee Medip Academy. This is an open-access article distributed under the terms of the Creative Commons Attribution Non-Commercial License, which permits unrestricted non-commercial use, distribution, and reproduction in any medium, provided the original work is properly cited.

\begin{abstract}
Background: Blood groups of women have been associated with infertility and other related conditions like diminished ovarian reserve. We have tried to find, if there is any association between blood group of women and the quality of their oocytes.

Methods: Present study is a retrospective analysis from the available data of IVF patients on standard ICSI protocols in our tertiary care clinic over 32 months. Oocytes were grouped into GOOD \& POOR quality oocytes. Good quality oocytes were further graded into Grade 1, 2, 3. SPSS 15.0 was used for statistical analysis.

Results: Good quality oocytes were almost similarly distributed among the blood groups. Among the good quality oocytes, Grade ' 1 ' Oocytes were found higher in ' $O$ ' blood group women.

Conclusions: Blood group alone was found to play no major role in determining the oocyte quality of women.
\end{abstract}

Keywords: Blood group, Oocyte quality, Age, PCO, Endometriosis, Ovarian reserve, Tubal block

\section{INTRODUCTION}

Female infertility contributes to $25 \%$ of the total infertility patients among the world. ${ }^{1}$ It is known that female infertility is affected by various factors like age, PCOD, endometriosis, ovarian reserve and tubal factor. ${ }^{2-6}$ These clinical conditions alter the oocyte quality. Oocyte quality is important for the early embryonic development, establishment and maintenance of pregnancy and also for normal fetal development (R. L. Krisher). ${ }^{7}$ In recent years blood group of women is also being explored as a factor contributing to infertility. ${ }^{8,9}$

The ABO blood group distribution among the indian population is given as $37.12 \%$ with blood group ' $\mathrm{O}$ ', followed by blood group 'B' (32.26\%), 'A' blood group $22.8 \%$ and ' $A B$ ' group only $7.74 \% .{ }^{10}$ Various studies report of the association of blood group of individuals with many major diseases like heart diseases, cancers etc. ${ }^{11}$ We for the first time have attempted to identify whether blood group affects the oocyte quality of women and also correlated it with the other clinical conditions known to cause female infertility.

\section{METHODS}

Study design: This is a retrospective, observational, single centred study, from the data of our IVF clinic located in Chennai, India.

Study period: Data of patients attending the IVF clinic in the time period between January 2012 - August 2014 were included.

\section{Study samples}

The quality of 685 oocytes retrieved from the records of 95 patients who underwent ICSI cycles in the given time 
frame was included in the study. Parameters taken into consideration were blood group, FSH, LH, E2, AMH values. Antral Follicular count was determined by Transvaginal scan. HSG was recommended wherever required. Based on these findings the patients were categorised into various clinical conditions contributing to female infertility such as poor ovarian reserve, endometriosis, PCO and Tubal Factor.

\section{Stimulation protocol}

All patients underwent stimulation with a flexible antagonist protocol similar to the standard ART antagonist protocol (C. Albano et al., 1996; F. Olivennes, et al., 1998). ${ }^{12,13}$

Briefly patients were started with Recombinant gonadotropin therapy, on the second day of their menstrual cycle. The initial dosage for stimulation was decided by their Age, BMI, Day 2 FSH value, Antral follicular counts, $\mathrm{AMH}$ value and by the presence or absence of Polycystic Ovarian Disorder (PCOD).

Follicular growth was monitored through ultrasound and serum hormonal assays of LH, and E2. When three or more lead follicles reached a size of $1.8 \mathrm{~cm}$ or more, 10000 units of hCG injection i.m. was given for final maturation and ovulation. After $35 \mathrm{~h}$ of $\mathrm{hCG}$ injection oocyte retrieval was done.

\section{Oocyte retrieval}

Transvaginal ultrasound - directed Oocyte retrieval was done, under GA. The follicular fluid was collected under $100-120 \mathrm{~mm} / \mathrm{Hg}$ pressure and was screened in the embryology lab. The cumulus complex oocytes were identified within the aspirated follicular fluid and then kept in pre-equilibrated $\left(37^{\circ} \mathrm{C}, 6 \% \mathrm{CO}_{2}\right)$ fertilization media (Sydney IVF fertilization medium, Cook, USA) for about an hour after which denudation was done with hyaluronidase.

The oocyte quality was determined and the oocytes were graded into GV, MI and MII according to nuclear maturity.

\section{Oocyte quality}

The denuded oocytes were morphologically evaluated with a colour video camera mounted on an inverted microscope at $\mathrm{x} 400$ magnification with Hoffman modulation contrast.

Oocyte maturation includes nuclear maturity and cytoplasmic maturity. Those oocytes where first polar body was not observed were termed as immature and were not included for ICSI Those Oocytes in which first polar body was observed, were considered mature M II oocytes, and were evaluated for further abnormalities and graded.

\section{Oocyte grading}

The abnormalities commonly observed in an oocyte include shape of the oocyte, granularity and homogeneity of the cytoplasm, size and debris in Perivitelline space, vacuolization, inclusions and abnormalities of the first Polar Body or of the Zona Pellucida. Good quality mature (M II) oocytes have a clear, homogenous cytoplasm, a small Perivitelline space, an ovoid or round first polar body with a smooth surface and clear colourless Zona Pellucida. $^{14}$

The MII oocytes were graded, where grade I oocytes have no abnormalities, Grade II oocytes have only one abnormality and Grade III oocytes have at least two abnormalities or more.

\section{Statistical analysis}

The 685 oocytes on ABO system were analysed using SPSS 15.0 and the results are presented as Descriptive statistics - Frequency, percentage, mean, standard error and inferential statistics - $\mathrm{X}^{2-}$ test of association, student-ttest for independent samples \& ANOVA with 5\% type I error and $20 \%$ type II error. The value within the parentheses represents percentages.

\section{RESULTS}

The analyses were done in two ways:

1. The 'Oocyte quality' was categorised as GOOD or POOR.

2. The 'Oocyte grading' categorised from POOR to GOOD [Immature/G3/G2/G1] were Scored as $0 / 1 / 2 / 3$

In this study oocytes 557 (81.3) were of 'GOOD' quality and 128 (18.7) oocytes were of 'POOR' quality. Among the GOOD oocytes, 120 (17.5) were G3 and 123 (18.0) \& 314 (45.8) were G2 \& G1 respectively. We observed 178 (26.0) \& 237 (34.6) belonged to A and B Blood groups, and 34 (5.0) \& 236 (34.5) were from $\mathrm{AB}$ and $\mathrm{O}$ Blood groups respectively. Table 1 presents the Descriptive Statistics for the Baseline parameters - age, ovarian reserve, endometriosis, PCO, tubal factor and the outcome parameters - Oocyte quality, oocyte grading alongwith their Chi-square value. Figure 1 presents the distribution of Oocyte quality (\%) based on ABO system. We did observe a statistically significant association between blood groups and oocyte grading $\left[\chi^{2}=110.5\right.$ $(\mathrm{P}=0.000)]$. Further confirmed a Significant Difference in the Mean Scores between the Blood groups for oocyte quality with $\mathrm{F}=12.07(\mathrm{P}=0.000)$ and is presented in Figure 2. We observed a maximum mean score 64.5 for the $\mathrm{O}$ blood group in $\mathrm{G} 1$, followed by $\mathrm{AB}, \mathrm{B} \& \mathrm{~A}$ group. Blood group A had a maximum mean score of G2 \& G3 with $33.7 \&$ 26.4. Among the Blood groups A \& B, 'Immature' oocyte was very much equally high. 
Table 1: Descriptive statistics for study parameters.

\begin{tabular}{|c|c|c|c|c|c|}
\hline \multirow[b]{2}{*}{ Parameters } & \multicolumn{4}{|c|}{ Blood groups - N (\%) } & \multirow{2}{*}{$\begin{array}{l}X^{2} \text { - value } \\
\text { ( } P \text { value) }\end{array}$} \\
\hline & $\begin{array}{l}\text { A } \\
178(26.0)\end{array}$ & $\begin{array}{l}\text { B } \\
237 \text { (34.6) }\end{array}$ & $\begin{array}{l}\text { AB } \\
34(5.0)\end{array}$ & $\begin{array}{l}O \\
236(34.5)\end{array}$ & \\
\hline \multicolumn{6}{|l|}{ BASELINE } \\
\hline \multicolumn{6}{|l|}{ 1. Age } \\
\hline a. $\leq 35$ & $142(20.7)$ & $227(33.1)$ & $29(4.2)$ & $227(33.1)$ & 44.12 \\
\hline b. $>35$ & $36(5.3)$ & $10(1.5)$ & $5(0.7)$ & $9(1.3)$ & $(0.000)^{*}$ \\
\hline \multicolumn{6}{|l|}{ 2. Ovarian reserve } \\
\hline a. GOOD & $161(23.5)$ & $225(32.8)$ & $34(5.0)$ & $236(34.5)$ & 24.75 \\
\hline b. POOR & $17(2.5)$ & $12(1.8)$ & $0(0.0)$ & $0(0.0)$ & $(0.000)^{*}$ \\
\hline \multicolumn{6}{|l|}{ 3. Endometriosis } \\
\hline a. Present & $23(3.4)$ & $5(0.7)$ & $0(0.0)$ & $15(2.2)$ & 22.63 \\
\hline b. Absent & $155(22.6)$ & $232(33.9)$ & $34(5.0)$ & $221(32.3)$ & $(0.000)^{*}$ \\
\hline \multicolumn{6}{|l|}{ 4. $\mathrm{PCO}$} \\
\hline a. Present & $59(8.6)$ & $59(8.6)$ & $3(0.4)$ & $53(7.7)$ & 11.67 \\
\hline b. Absent & $119(17.4)$ & $178(26.0)$ & $31(4.5)$ & $183(26.7)$ & $(0.009)^{*}$ \\
\hline \multicolumn{6}{|l|}{ 5. Tubal factor } \\
\hline a. Patent & $10(1.5)$ & $23(3.4)$ & $0(0.0)$ & $0(0.0)$ & 26.25 \\
\hline b. Block & $168(24.5)$ & $214(31.2)$ & $34(5.0)$ & $236(34.5)$ & $(0.000)^{*}$ \\
\hline \multicolumn{6}{|l|}{ Outcome } \\
\hline \multicolumn{6}{|l|}{ 6. Oocyte quality } \\
\hline a. GOOD & $143(20.9)$ & $188(27.4)$ & $30(4.4)$ & $196(28.6)$ & 2.26 \\
\hline b. POOR & $35(5.1)$ & $49(7.2)$ & $4(0.6)$ & $40(5.8)$ & $(0.518)$ \\
\hline \multicolumn{6}{|l|}{ 7. Oocyte grading } \\
\hline a. Immature & $35(5.1)$ & $49(7.2)$ & $4(0.6)$ & $40(5.8)$ & \\
\hline b. G3 & $47(6.9)$ & $42(6.1)$ & $0(0.0)$ & $31(4.5)$ & $\begin{array}{l}110.55 \\
(0000) *\end{array}$ \\
\hline c. G2 & $60(8.8)$ & $40(5.8)$ & $10(1.5)$ & $13(1.9)$ & \\
\hline d. G1 & $36(5.3)$ & $106(15.5)$ & $20(2.9)$ & $152(22.2)$ & \\
\hline
\end{tabular}

*Statistically significant at $5 \%$

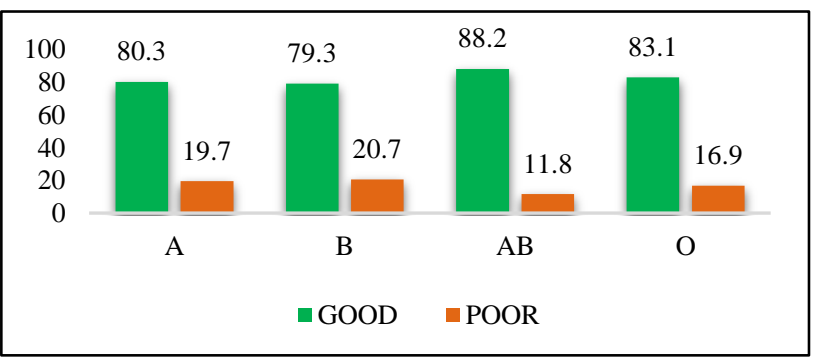

Figure 1: Oocyte quality $(\%)$.

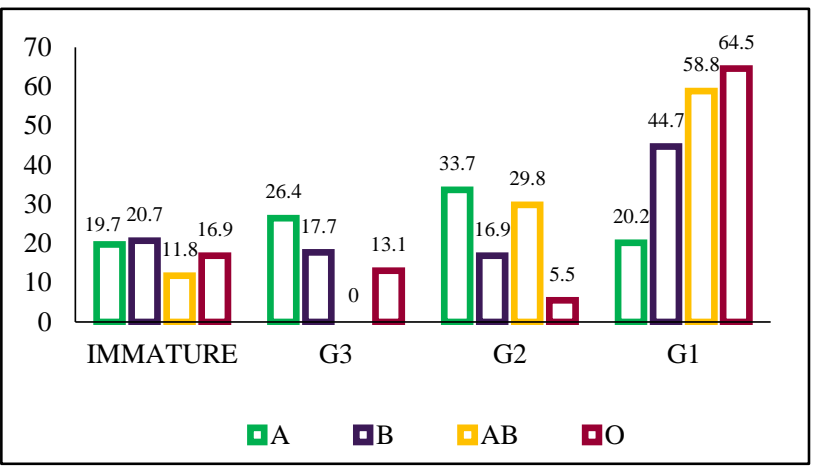

Figure 2: Mean score of oocyte grading.
When we tried to find the difference in mean scores between two blood groups, student-t-test showed significance for all combinations other than the $\mathrm{AB}$ and $\mathrm{O}$ blood group. Table $2 \&$ Figure 3 show the mean scores of oocyte grading for the five baseline parameters of $\mathrm{ABO}$ system. The oocyte from the age greater than 35 years did have the equal mean scores compared to the age less than or equal to 35 for A, B \& AB blood groups. With GOOD ovarian reserve, there existed a significant increase in the oocyte quality and the Absence of endometriosis still increased mean scores of oocyte for A, B \& O blood groups. The 'presence' of PCO had equal mean score as compared to its counterpart and 'blocked' tubal factor did have a closer mean score compared to a 'patent' one for A \& B blood groups.

The main findings of the study are as follows:

1. There existed a statistically significant association between the blood groups and oocyte grading.

2. The mean Score of oocyte grading - G1 was observed to be high in the ' $O$ ' blood group followed by ' $A B$ ' and was statistically significant.

3. Age did not show any significant difference in mean scores of oocyte grading from B \& AB groups. 
Table 2: Inferential statistics for oocyte grading score.

\begin{tabular}{|c|c|c|c|c|}
\hline \multirow[b]{2}{*}{ Parameters } & \multicolumn{4}{|c|}{ Oocyte grading score } \\
\hline & $\begin{array}{l}A \\
\text { Mean } \pm S E \\
{[\text { t-value (P value) }]}\end{array}$ & $\begin{array}{l}\text { B } \\
\text { Mean } \pm \mathrm{SE} \\
{[\mathrm{t} \text {-value (P value)] }}\end{array}$ & $\begin{array}{l}\mathrm{AB} \\
\mathrm{Mean} \pm \mathrm{SE} \\
{[\mathrm{t} \text {-value (P value)] }}\end{array}$ & $\begin{array}{l}O \\
\text { Mean } \pm S E \\
{[t-v a l u e(P \text { value })]}\end{array}$ \\
\hline $\begin{array}{l}\text { 1. Age } \\
\begin{aligned} \text { a. } & \leq 35 \\
\text { b. } & >35\end{aligned}\end{array}$ & $\begin{array}{l}1.46 \pm 0.08 \\
1.89 \pm 0.16 \\
{\left[2.28(0.024)^{*}\right]}\end{array}$ & $\begin{array}{l}1.86 \pm 0.07 \\
1.80 \pm 0.49 \\
{[0.152(0.879)]}\end{array}$ & $\begin{array}{l}2.41 \pm 0.19 \\
2.00 \pm 0.00 \\
{[0.868(0.392)]}\end{array}$ & $\begin{array}{l}2.14 \pm 0.08 \\
3.0 \pm 0.00 \\
{\left[2.13(0.03)^{*}\right]}\end{array}$ \\
\hline $\begin{array}{l}\text { 2. Ovrian reserve } \\
\text { a. GOOD } \\
\text { b. POOR }\end{array}$ & $\begin{array}{l}1.59 \pm 0.07 \\
1.12 \pm 0.28 \\
{\left[1.81(0.07)^{*}\right]}\end{array}$ & $\begin{array}{l}1.91 \pm 0.08 \\
0.92 \pm 0.23 \\
{\left[2.82(0.005)^{*}\right]}\end{array}$ & $\begin{array}{l}2.35 \pm 0.16 \\
0 \pm 0.0 \\
-\end{array}$ & $\begin{array}{l}2.17 \pm 0.07 \\
0 \pm 0.0 \\
-\end{array}$ \\
\hline $\begin{array}{l}\text { 3. Endometriosis } \\
\text { a. Present } \\
\text { b. Absent }\end{array}$ & $\begin{array}{l}0.83 \pm 0.08 \\
1.65 \pm 0.08 \\
{\left[3.73(0.000)^{*}\right]}\end{array}$ & $\begin{array}{l}1.00 \pm 0.00 \\
1.88 \pm 0.07 \\
{[1.62(0.106)]}\end{array}$ & $\begin{array}{l}0 \pm 0.0 \\
2.35 \pm 0.16 \\
-\end{array}$ & $\begin{array}{l}2.2 \pm 0.31 \\
2.17 \pm 0.08 \\
{[0.08(0.93)]}\end{array}$ \\
\hline $\begin{array}{l}\text { a. Present } \\
\text { b. Absent }\end{array}$ & $\begin{array}{l}1.64 \pm 0.11 \\
1.50 \pm 0.10 \\
{[0.908(0.365)]}\end{array}$ & $\begin{array}{l}1.73 \pm 0.16 \\
1.90 \pm 0.08 \\
{[0.944(0.346)]}\end{array}$ & $\begin{array}{l}- \\
2.0 \pm 1.0 \\
2.39 \pm 0.16 \\
{[0.647(0.52)]}\end{array}$ & $\begin{array}{l}1.87 \pm 0.17 \\
2.26 \pm 0.08 \\
{\left[2.13(0.034)^{*}\right]}\end{array}$ \\
\hline $\begin{array}{l}\text { 5. Tubal factor } \\
\text { a. Patent } \\
\text { b. Block }\end{array}$ & $\begin{array}{l}1.53 \pm 0.08 \\
1.80 \pm 0.20 \\
{[0.809(0.42)]}\end{array}$ & $\begin{array}{l}1.84 \pm 0.08 \\
2.04 \pm 0.26 \\
{[0.786(0.432)]}\end{array}$ & $\begin{array}{l}2.35 \pm 0.16 \\
0 \pm 0.0 \\
-\end{array}$ & $\begin{array}{l}0 \pm 0.0 \\
2.17 \pm 0.07 \\
-\end{array}$ \\
\hline
\end{tabular}

*Statistically significant at $5 \%$

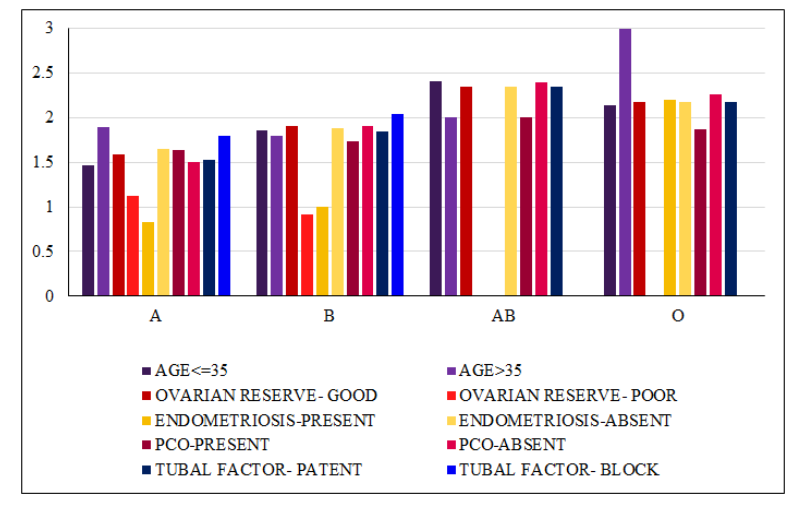

Figure 3: Mean score of oocyte grading.

\section{DISCUSSION}

The present study was to find if any significant association exists between the oocyte quality and different blood groups. Our findings show a significant association of oocyte grading and the ABO blood group system. The grade ' 1 ' oocytes or the best quality oocytes are distributed more among the ' $\mathrm{O}$ ' blood group women (Figure 2). This observation might add value to the various studies which state that incidence of infertility is high among the 'O' blood group women by proving that oocyte quality need not be the only contributing factor for infertility. ${ }^{9,15} \mathrm{We}$ also found that in women of $\mathrm{AB}$ blood group, good quality oocytes (Grade ' 1 ', Grade ' 2 ' and
Grade ' 3 ' together), were found to be high though the difference is not much when compared with other blood groups. There is evidence to suggest that ' $A B$ ' group as the most fertile group which is also shown in our study where next to $\mathrm{O}$ group $\mathrm{AB}$ group had highest number of good Grade 1 oocyte.

It is well established, that age is a major factor affecting the female fertility. ${ }^{2,3}$ In our study we observed that blood group of women did not act as an add on factor for infertility among women i.e. we found no clinical significance for oocyte quality among the various age groups in correlation to the ABO Blood Group System. Surprisingly we also noticed that women in higher age group (>35 years) also had a similar oocyte quality to the younger age group, irrespective of their blood group type. This suggests that age per se may affect the reserve of the ovaries (actual number of oocytes) but not the quality of the oocytes. This is in contradiction to the available studies so far which correlate age with poor oocyte quality. Further prospective studies with larger sample size may be required to delve deeper into this hypothesis.

In blood groups ' $A$ ' and ' $B$ ', there is an increase in the mean oocyte score for good ovarian reserve. But we were not able to compare the oocyte quality distribution for ' $\mathrm{AB}$ ' and ' $\mathrm{O}$ ' blood groups with ovarian reserve, since our study population did not include any women with Diminished Ovarian Reserve (DOR) among these blood groups. This observation was against the findings of 
Netaj et al., who claimed that the blood group ' $\mathrm{O}$ ' favoured diminished ovarian reserve. ${ }^{9}$ Though our sample size was the largest in blood group ' $\mathrm{O}$ ' we found no women with DOR. In blood group 'B', the mean score of oocyte quality varied hugely between poor and good ovarian reserve, unlike blood group ' $\mathrm{A}$ ', where the mean oocyte score was similar for both the clinical conditions. This shows that antigen ' $A$ ' of the blood group may act as a protective agent as Netaj et al. suggested.

We observed a significant association of endometriosis with blood group 'A'. Previous studies have revealed that women with blood group ' $A$ ' are susceptible to endometriosis. ${ }^{16}$ Our observation also suggests that the quality of oocytes in such women may be greatly compromised. Other blood groups showed no significant association with endometriosis and respective oocyte quality. Similarly, it has been shown that women with blood group ' $\mathrm{O}$ ' are susceptible to $\mathrm{PCO}^{15}$ and we also found a significant association of the same. This finding suggests that ' $\mathrm{O}$ ' blood group women with PCO may have greatly altered oocyte quality. No association was found between tubal factor and oocyte quality among the blood groups.

Our findings show that Oocyte quality was more or less similarly distributed among the four blood groups and also suggest that blood group alone is found to have no association with oocyte quality. But there exists a significant association between Oocyte quality and Blood group in patients with Endometriosis and PCO.

\section{Funding: No funding sources}

Conflict of interest: None declared

Ethical approval: Not required

\section{REFERENCES}

1. Sasikala Natarajamani, Dakshinamoorthy Janani, Mahalakshmi Subramanian, Archana Manikere. Correlation of Semen $\mathrm{pH}$ with other Semen parameters in a sub fertile male population attending a tertiary art center in south India. Int J Sci Res Publicat (IJSRP). 2014 Aug;4(8):1-5.

2. Dunson David B, Donna D. Baird, Bernardo Colombo. Increased infertility with age in men and women. Obstet Gynecol. 2004;103(1):51-6.

3. Hull MG, Fleming CF, Hughes AO, McDermott A. The age-related decline in female fecundity: a quantitative controlled study of implanting capacity and survival of individual embryos after in vitro fertilization. Fertil Steril. 1996;65(4):783-90.

4. Jennifer R. Wood, Daniel A. Dumesic, David H. Abbott, Jerome F. Strauss III. Molecular abnormalities in oocytes from women with polycystic ovary syndrome revealed by microarray analysis. J Clin Endocrinol Metab. 2007;92(2):70513.

5. De Ziegler Dominique, Bruno Borghese, Charles Chapron. Endometriosis and infertility: pathophysiology and management. Lancet. 2010;376(9742):730-8.

6. Scott RT, Opsahl MS, Leonardi MR, Neall GS, Illions EH, Navot D. Infertility: life table analysis of pregnancy rates in a general infertility population relative to ovarian reserve and patient age. Hum Reprod. 1995;10(7):1706-10.

7. Krisher RL. The effect of oocyte quality on development. J Animal Sci. 2003;82:E14-23.

8. Spitzer D, Corn C, Stadler J, Wirleitner B, Schuff M, Vanderzwalmen $\mathrm{P}$, et al. Implications of blood type for ovarian reserve and infertility - impact on oocyte yield in IVF patients. Geburtshilfe Frauenheilkund. 2014;74(10):928-32.

9. Nejat EJ, Jindal S, Berger D, Buyuk E, Lalioti M, Pal L. Implications of blood type for ovarian reserve. Hum Reprod. 2011;26(9):2513-7.

10. Amit Agrawal, Aseem Kumar Tiwari, Nidhi Mehta, Prasun Bhattacharya, Ravi Wankhede, Sunita Tulsiani, et al. ABO and Rh (D) group distribution and gene frequency; the first multicentric study in India. Asian J Transfus Sci. 2014;8(2):121-5.

11. Ganitha G, Shirish Bhumkar, J. Bhuvaneswari. Association of $\mathrm{ABO}$ blood groups and infertility. Int J. 2012;2(5):72-7.

12. Albano C, Smitz J, Camus M, Riethmuller-Winzen $\mathrm{H}$, Siebert-Weigel M, Diedrich $\mathrm{K}$, et al. Endocrinology Hormonal profile during the follicular phase in cycles stimulated with a combination of human menopausal gonadotrophin and gonadotrophin-releasing hormone antagonist (Cetrorelix). Hum Reprod. 1996;11(10):2114-8.

13. Olivennes F, Alvarez S, Bouchard P, Fanchin R, Salat-Baroux J, Frydman R. The use of a GnRH antagonist (Cetrorelix) in a single dose protocol in IVF-embryo transfer: a dose finding study of 3 versus 2 mg. Hum Reprod. 1998;13(9):2411-4.

14. Mikkelsen, Anne Lis, Svend Lindenberg. Morphology of in vitro matured oocytes: impact on fertility potential and embryo quality. Hum Reprod. 2001;16(8):1714-8.

15. Rahul Pal, Pratik Kumar Chatterjee, Poulomi Chatterjee, Vinodini NA, Prasanna Mithra, Sourjya Banerjee, et al. Polycystic Ovary syndrome, blood group \& diet: a correlative study in South Indian females. Int J Med Res Health Sci. 2014;3(3):604-9.

16. Matalliotakis I, Cakmak H, Goumenou A, Sifakis S, Ziogos E, Arici A. ABO and $\mathrm{Rh}$ blood groups distribution in patients with endometriosis. Arch Gynecol Obstet. 2009 Dec;280(6):917-9.

DOI: $10.18203 / 2320-1770.1 j \mathrm{rcog} 20150083$

Cite this article as: Natarajamani ST, Thiagarajamurthy D, Subramanian M, Janani Moorthy D, Bhargav A, Parameaswari PJ. Oocyte quality and ABO blood group system: are they connected? Int J Reprod Contracept Obstet Gynecol 2015;4:735-9. 